This item was submitted to Loughborough's Research Repository by the author.

Items in Figshare are protected by copyright, with all rights reserved, unless otherwise indicated.

\title{
Cyborg and supercrip: the paralympics technology and the (dis)empowerment of disabled athletes
}

PLEASE CITE THE PUBLISHED VERSION

http://dx.doi.org/10.1177/0038038511413421

PUBLISHER

SAGE $\odot$ The Author

VERSION

SMUR (Submitted Manuscript Under Review)

\section{PUBLISHER STATEMENT}

This work is made available according to the conditions of the Creative Commons Attribution-NonCommercialNoDerivatives 4.0 International (CC BY-NC-ND 4.0) licence. Full details of this licence are available at: https://creativecommons.org/licenses/by-nc-nd/4.0/

\section{LICENCE}

CC BY-NC-ND 4.0

\section{REPOSITORY RECORD}

Howe, P. David. 2019. "Cyborg and Supercrip: The Paralympics Technology and the (dis)empowerment of Disabled Athletes". figshare. https://hdl.handle.net/2134/15942. 


\title{
Cyborg and Supercrip: The Paralympics technology and the (dis)empowerment of disabled athletes.
}

\begin{abstract}
Over the last two decades the Paralympic Games have gained a high public profile. As a result there has been an ever increasing commercial marketplace for aerodynamic and feather light racing (wheel)chairs as well as biomechanically and ergonomically responsive prostheses that have helped create a legion of cyborg bodies that is manifest in the image of the sporting supercrip. Mobility devices that enhance performance have also created a divide between different impairment groups but also amongst 'developed' and ‘developing' nations. This paper highlights the development of a technocentric ideology within the Paralympic Movement that has led to the cyborgification of some Paralympic bodies. It questions whether the advances in technology are actually empowering disabled athletes.
\end{abstract}

Keywords: Cyborg, disability, Paralympics, supercrip, technology

Issues concerning eligibility for elite sporting contests may have never been more debated than when South African 400m runner Oscar Pistorius decided that he was searching for a new challenge. Pistorius is a bi-lateral below the knee amputee who came to the attention of those interested in Paralympic sport following his success in the Athens 2004 Paralympic Games. In that event Pistorius destroyed the field in the $200 \mathrm{~m}$ setting a new world record in a race that included athletes that were uni-laterial below the knee amputee and considered to be less impaired than him. It was clear that Pistorius was a unique athlete not only for his physical achievements, but also because an absence of lower limbs required the adoption of two prosthetic limbs that have catapulted him beyond the horizon of the Paralympic movement to the point where he was a few strides away from eligibility in the Olympics. Athletes such as 
Pistorius that have amputated lower limbs often run on carbon fibre 'blades' that act as feet and as a result Pistorius has been referred to as the Blade Runner (Hunt-Grubbe, 2007; Morrissey, 2008; Swartz and Watermeyer, 2008). The utilising of such technology by Paralympic athletes means that they can be conceptualised as the embodiment of Haraway's (1991) cyborg that is a hybrid body resulting from fusion of a live organism and man-made technology. It is the Paralympian cyborg, rather than Pistorius himself, that is at the heart of the research presented here.

In the context of Paralympic sport the most successful cyborg athletes may be seen as 'supercrips'. Following Berger supercrips “are those individuals whose inspirational stories of courage, dedication, and hard work prove that it can be done, that one can defy the odds and accomplish the impossible.” (2008, p. 648). It also has been argued that the label of supercrip can be negatively bestowed upon impaired individuals who simply manage to live ‘an ordinary’ life (Kama 2004). Specifically in the context of Paralympic sport and for the purpose of this paper the supercrip is the athlete who wins and also gains a relatively high profile media exposure. Those athletes who win but do not receive recognition in mainstream media are not supercrip in the context of the Paralympics as they are often marginalised by the degree or nature of their impairment. This marginalisation is in part determined by the classification process that sports people with impairments must undergo in order to determine their eligibility to compete. Also of importance in this paper is whether or not athletes use mobility technologies and, by extension, the degree to which they are cyborgs. The process of making a cyborg I articulate as cyborgification as it is useful to understand that in the contemporary world all our bodies some way use technology. Our bodies can be placed along a continuum from those that require very 
little technological aid to those whose lives benefit from a great deal from technology. Paralympian wheelchair racers and prosthetic wearing athletes are the most explicit examples of cyborgification in sport today.

This paper will explore the interrelatedness of the process of classification of athletes within Paralympic sport and issues of cyborgification and the supercrip, that surround the mobility technologies which facilitate the participation of athletes who would be unable to practice their chosen sport without them. To begin, the paper will briefly highlight the central importance of classification within the practice of Paralympic sport and how this accentuates different forms of impairment that relate in very particular ways to mobility technologies. As such, throughout the paper I will refer directly to these impairment forms as this is standard practice within Paralympic culture ${ }^{1}$. Following this the paper will consider technology and how the process of continual advancement and development of two particular mobility aids (wheelchairs and prosthetic limbs) used in track and field athletics have led to the Paralympic Games becoming increasingly commercial and successful in attracting sustained levels of media coverage. As a result of the influence of technology certain impaired bodies of athletes may be seen as a product of cyborgification, that ultimately leads to the successful competitors being seen as supercrips (Berger, 2004, 2008). Bodies that are the product of cyborgification, so it will be argued, are the vanguard of the sport for the disabled and as such they are celebrated far more than those competitors that do not use mobility technologies. The paper will conclude by asking whether the advances in technology are actually empowering disabled athletes.

\section{Classification and its Centrality in Paralympic Sport}


The International Paralympic Committee (IPC) currently organises and administers both the Paralympic Games and the quadrennial World Championships for individual Paralympic sports such as athletics. Using the resources of the International Organisations of Sport for the Disabled (IOSD)(Author) ${ }^{2}$ (including athletes, volunteer administrators, and classification systems) the IPC has made the Paralympic Games into the most recognisable and influential vehicle for the promotion of disability sport.

Classification is central to the structuring of competition in Paralympic sport, similar to the systems used in the sports of judo and boxing where competitors perform in distinctive weight categories (Author; Author). Within the Paralympics competitors are classified by their body's degree of function within their chosen sport. Classification takes the form of a series of functional tests that determine the appropriate category in which to place the athlete so that equitable sporting contests can be achieved (Sherrill, 1999) and as such is a fundamental component of Paralympic culture (Author). It is a process that is conducted by a group of qualified classifiers who have between them an expertise in physical impairments and the sporting practice in which they are classifying athletes. The classification process used by the IOSDs is a form of selective classification (Tweedy and Vanlandewijck, 2009) that makes a distinction between the physical potential of athletes. The successful athletes in each class should have an equal chance of accumulating physical capital (Author). In reality however there are a number of factors that impact upon the accumulation of capital (both physical and cultural) in various classifications the most salient of which for the purpose of this paper is whether or not the athlete uses mobility technologies while they perform. For example the wheelchair is the ubiquitous symbol for disability. The ever-present iconography of the wheelchair in disabled 
parking bays, for example, means that the public can relate easily to this mobility technology in the context of Paralympic sport. There has also been research to suggest that within Paralympic sport there is a hierarchy of 'acceptable' impairment within the community of athletes (Sherrill and Williams, 1996; Schell and Rodriguez, 2001). As a result it reinforces the position of wheelchair athletes on the top of a hierarchy of disabilities that locates the less socially acceptable disability categories as marginal (Kama, 2004; Haller, 2000; Mastro, Burton, Rosendahl \& Sherrill, 1996). Another factor that impacts upon the accumulation of capital is the number of athletes within a particular event. If a competition has six athletes and another has three times that many the winner of the latter is like to gain more capital because more individuals are beaten to secure the victory. A further important factor in terms of whether winners ultimately gain capital from their involvement in sport is the nature and degree of their impairment. The more minimally impaired a wheelchair athlete is for example the more likely that they will become the embodiment of the supercrip (Berger, 2004, 2008).

The original classification system that was developed by the International Wheelchair and Amputee Sport Association (IWAS) can be understood as a major reason why wheelchair athletes are celebrated ahead of athletes from other impairment groups. This system classified athletes with spinal cord injuries according to where the lesion was in their spine because back function is of great importance in sport. It was believed that athletes with a greater level of function in their spine should be in a different class from those athletes that have less. Athletes who were leg amputees could easily be fitted into the most able class in this system as they had full use of the spine. It was the IWAS system that was at the heart of the establishment of the Paralympic movement and which all other impairment groups had to petition to join in the early 
days of the movement. As an increasing number of athletes with different impairments aspired to get involved in sport for the disabled IWAS established a broad class known as les autre ${ }^{3}$. Some les autre athletes that use wheelchairs, including those with spina bifida and polio, were able to be slotted into the IWAS system, but it was and never has been an exact science. However many les autre were ineligible because they did not need to use a wheelchair and this ineligibility eventually led to the development of the remaining IOSDs and, ultimately, the development of the IPC. In this way, the classification system that led to the development of sport for the disabled was not political or culturally neutral.

It is often supposed that one of the goods delivered by successful science is the right way of classifying the things in the world. Surely there is something right about this: any body of scientific knowledge will include ways of classifying, and will not serve its intended aims unless the classifications it embodies reflect real differences and similarities in the world (Dupré, 2006:30).

Following Dupré, a philosopher of science, we can see that a classification system can be developed to make sense of the world, in this case that of Paralympic sporting practice. Importantly, however, Dupre adds a caveat to the statement above suggesting

there is a highly questionable implication of there being some unique best classification ...Classifications are good and bad for particular purposes, and different purposes will motivate different classifications (Dupré 2006:30) 
In other words the systems of classification developed and adopted within the cultural context of Paralympic sport are the product of the history of this practice. Since the history of the Paralympic movement places athletes in wheelchairs ${ }^{4}$ at its centre in part because athletes with spinal cord injuries and amputations were the first to compete in disability sport (Author) it is likely that the classification system currently in place continue to favour these athletes who are reliant on constantly improving mobility technologies to enhance their performances. It is to the issue of mobility technology development that this paper now turns.

\section{Wheelchairs in Track and Field Athletics}

In the mid 1980s racing wheelchairs were four wheeled and cumbersome by the standards of today's state of the art technology, but they were a significant improvement on the technologies

of the rehabilitative sport era of the Paralympic movement (Author). Specially designed racing wheelchairs may be seen as the first major step toward a high performance Paralympic Games. Indeed performances in terms of speeds of the track events at the Paralympic Games have been improving with the turning of every Paralympiad. For example, the able bodied male $800 \mathrm{~m}$ world record during the 1980s stood at 1:41.73 and the record at the time of writing is 1:41.11. The record for wheelchair racers from the 1980s was 1:55.67 and the record today is 1:32.17. Over this period wheelchair racers have gone from being considerably slower than their able bodied counterparts over the same distance to significantly faster in part due to advances in wheelchair technology. The rules of wheelchair racing also allow for drafting which is an additional factor in the improved performances and as a result elite races on the track are similar (at least in terms of tactics) to road cycling where drafting is an advantageous way to save energy. The desire of athletes to move better and faster and also to assist in the production of 
technology by offering expert advice has allowed them to achieve these aims. However, developing improved technology is only half the battle. First of all technologies develop at different rates. Some nations might make advances in performance simply because of their access to superior technology. Medal tables at the Paralympic Games have been traditionally dominated by Western nations in part because they are at the forefront of the technological advancements in mobility apparatus. Like the Cold War arms race the Paralympic Movement quite literally, in the race to produce the most efficient and advanced mobility aids, has a leg race on its hands.

Today's high performance racing wheelchair has three wheels, is aerodynamically built of lightweight carbon fibre so that developing more speed takes considerably less effort than it did in the heavier models of two decades ago. The frame is ' $\mathrm{T}$ ' shaped which provides both stability, through the long front and a degree of rigidity both of which are required when the chairs travel at high speeds (Yilla, 2000). Racing machines with very thin highly pressurized tires and a carbon fibre frame that year on year weigh less and less also benefits from a steering mechanism called a compensator. This is a technology that has been developed to allow wheelchair racers to 'forget' about turning their chairs through a corner. The compensator can be set to direct the chair around the bend once it has been activated by the athlete. Compensators are fixed to the front wheel axial so that the athlete hits it upon entering and exiting a turn. This is all racers have to concern themselves with (that is apart from the art of racing) while on the bend. This technological advance has allowed racers to improve their performances markedly. 
Within track and field athletics throwing events (discus, javelin, shot put and $\operatorname{club}^{5}$ ) wheelchairs have, since the early 1990s, been replaced by throwing frames which do not have wheels. These frames are more robust than a wheelchair and as a result they are easier to make into a solid platform for competition. The frame is tied to a series of points on the ground either in a shot put or discus circle or behind the line on the javelin 'run-up'. Each frame is specifically designed for the athlete and as such enables them to get the most out of their throwing technique. The complex nature of the technique associated with throwing implements such as the shot, discus and javelin means that the rules regarding seated throws have come under close scrutiny in recent years (Frossard et al, 2006). Some classes of athletes are not allowed to let their gluteus leave the seat of the throwing frame. Breaking of this rule has been monitored increasingly by officials at top level events including the Paralympic Games and IPC World Championships. Those throwers who are able to use their legs as well as their upper body ultimately face the prospect of being reclassified into a more able class since the use of one's legs can be an obvious advantage in a sport where the longest distance thrown in six attempts establishes the winner.

There has also been concern about the use of materials in the frames that allow for a 'spring like response' to the throwing action. Athletes hold onto a pole that is part of his or her frame and recoils the body and then releases the implement. Excess energy generated by this action cannot force the body outside the throwing area. In other words if the force from the pole is so great it allows the body to break the plane of the throwing arena the resulting effort will be considered a foul. What is important with regards to discussions about technology is that there is a strong correlation between 'the interaction between the design of the athlete's throwing frame and their 
throwing technique' (Frossard et al, 2006:1). In other words the synergy between the frame and the body produces a cyborg.

For the top racers and throwers their wheelchairs and throwing frames are now an extension of their bodies. These athletes are all individuals who are accustomed to using a wheelchair for mobility, to the degree that moving in a wheelchair becomes habitual, and allows them to develop a hybrid body (Haraway, 1991:178). While this is the case with wheelchair racers and throwers it is perhaps more self evident with users of prosthetic limbs.

\section{From Wooden Leg to Carbon Fibre Blade}

Perhaps the most popular imagery of the past associated with prosthetic limbs is that associated with the haggard old 'sea dog' who hobbles around on a wooden peg-leg. These wooden prostheses have a long history and are more than adequate mobility aids (Chaloner et al, 2001; Webling and Fahrer, 1986). The term prosthesis is Greek for an addition designed to remove physical stigma.

Prosthetic medicine is dedicated to physical normalisation and is devoted to the artificial alteration of both function and appearance, but it enters the realm of biopolitics because it uses the 'normal' body as its tribunal and blueprint for action, and treats the impaired body as a spoilt entity that must be hidden and corrected (Hughes, 2000:561) 
There is a desire to 'create' the normal and at the same time allow individuals to be more mobile and therefore independent. In the context of sports participation as well as day to day mobility one of the problems associated with traditional technology is the development of pressure ulcers and painful stumps that develop where the prosthesis joins the body (DesGroseillers et al, 1978). Such dermatologic ailments are at their most painful during the process of rehabilitation where part of gaining an ability to use a prosthetic limb means the skin at the point of contact needs to 'toughened up' (Rossi, 1974). This is particularly acute for leg amputees ${ }^{6}$ as the act of bearing weight on a prosthesis can create pressure on the 'stump' that is the result of the amputation. Regardless of technological advances the pull of gravity means that this pressure will pose an ongoing challenge.

Since 1988 there has been a marked improvement in the technology, particularly in western nations, associated with leg prosthetics. The materials from which prostheses are made have changed markedly from wood to fibreglass to all manner of carbon fibre and lightweight metals used in advanced scientific design. These mobility aids have been a product of state of the art technologies and as a result the athletes who are the vanguards of the deployment of this new technology are producing performances that would have been considered impossible twenty years ago. It can be argued that this sporting technology has advanced with three aims in mind: to produce better performances; to increase the comfort for an individual, athlete or otherwise; and to enable an improvement in efficiency of movement. Advancement is most evident on the track, but also in field events where athletes with amputations have the option of competing as standing athletes or as athletes who use throwing frames. Traditionally a large percentage of track and field athletes with full or partial leg amputations have for reasons of comfort competed 
from a wheelchair. The treatment of the nexus between the prosthesis and the body has developed at pace with the actual replacement limb. Today the top of the range 'flex foot' legs are built around the individual's stump and are secured in place by a vacuum seal device which often includes gel padding which greatly reduces the risk of injury from swelling and friction (Author).

The use of flex-foot technology that is used instead of the old fashioned prosthesis, where flexion of the ankle was either mechanical or non-existent, is universal at the highest level of Paralympic sport. As a result there is little advantage to having this technology once you are at the Paralympic Games, but it is required to get there. Countries who are at the developmental stages of sport for the disabled programmes may find it unrealistic to train runners and throwers in leg amputee classes as the cost of up to date the technology can be prohibitive. This is a problem with the leg race for technology. With state of the art racing wheelchairs costing upwards of $£ 5000$ and ergonomically designed prosthesis costing up to £20,000 athletes from across the global can find participation as cyborgs with state of the art technology prohibitive. While the technology is becoming more affordable there will likely always be nations and athletes left behind in the leg race. Therefore eligibility can be limited by economic factors as well as physical ones. Performance standards, however, have improved dramatically across the board within the classification of leg amputees in large part due to increased accessibility to state of the art technology. As the technology becomes more affordable there are likely to be as many ambulant cyborgs competing as there are currently in wheelchairs. 
The previous two sections of the paper have highlighted the development of both wheelchairs and prosthetic limbs. Attention is now turned to the notion that such developments signal a 'technocratic ideology' that Shogun (1998) has suggested is becoming increasingly pervasive within the Paralympic movement.

\section{Technocratic Ideology}

The technological innovations discussed in the two preceding sections are important factors in helping to focus the Paralympic spotlight on athletes that are members of IWAS. It is important however to remember that these technologies have to be purchased and therefore the Paralympic movement represents a developing market for the sale of technologically advanced mobility aids. As such, many of the most up to date mobility technologies highlighted in this paper are inaccessible to athletes from much of the 'developing' world where the population is generally poorer. In this sense Paralympic athletics may be seen as technologically advanced on the one hand, but isolationist and exclusionary on the other. In other words the importance of technology in the context of Paralympic track and field athletics can best be expressed in the phrase 'technocentric ideology'(Charles, 1998: 379).

The move to hi-tech mobility devices specifically designed for sport is a response the general push for more technological advancement in society but it also relates to the desires of the athletes to perform with greater proficiency. Today many of the elite athletes work with leading wheelchair and prosthesis suppliers to ensure their future success is based on the technologies they use as much as it is the training regimes they follow. As a result the top cyborg athletes also receive commercial reward for their involvement in the development and manufacture of state- 
of-the-art technology that is at the heart of technocratic ideology. In other words technology is literally pushing the Paralympic Movement. As Charles suggests

Technology and kinesiology are symbiotically linked. They have a mutually beneficial relationship. As technology advances, so does the quality of scientific research and information accessible in the field. As kinesiology progresses and gains academic acceptance and credibility, technology assumes a more central role in our field. The more scientific the subdiscipline, the more we can see technology at play (1998: 379)

Following this statement it is clear that the field of high performance sport (of which Paralympic sport is a subset) has benefited from an increase in technologies that have been developed to harness the power of the human body (Davis and Cooper, 1998; Burkett, 2010). Able-bodied ${ }^{7}$ high performance athletes rely on technology in their day to day training (Hoberman, 1992; Shogun, 1999) yet when these athletes perform in sports like track and field athletics the technology that has allowed them to train and compete in the sporting arena may be completely obscured from view. An able-bodied athlete does take technology with him or her to the start of an Olympic final as their clothing and footwear are products of advanced technology. In fact Butryn (2002, 2003) has highlighted that high performance (able bodied) track and field athletics is surrounded by technologies that enable athletes to become cyborgs. However, specialist clothing and shoes appear less like advanced technology in comparison to racing wheelchairs and prosthetic limbs, that lead to the cyborgification of bodies, as they are not explicitly aids for mobility. As Shogun suggests: 
When persons with disabilities use technologies to adjust the participation in "normal" physical activity, the use of these technologies constructs this person as unnatural in contrast to a natural, nondisabled participant, even though both nondisabled participants and those with disabilities utilize technologies to participate (Shogun, 1998: 272)

Technologies such as racing wheelchairs and flex-feet (artificial legs biomechanically designed for running) have enhanced the performances of athletes whose impairments benefit from their use and are central to the identity of the Paralympic movement. It is these cyborg sporting bodies that are most often celebrated by the IPC (Author). Bodies that are able to successfully adapt to technology that wherever possible normalises their movements within society generally and on the athletics track specifically are seen as (the most) successful. According to Seymour

A winning wheelchair athlete is seen as the epitome of rehabilitative success. The vision of strong male bodies competing for honours on the sports field is an image that has currency in the able-bodied world. Bravery in overcoming the catastrophe of a damaged body is a quality everyone can admire (Seymour, 1998: 119)

This image extends to amputee athletes who have also suffered traumatic injuries and use performance-enhancing prosthetic limbs. The use of mobility technologies provides an opportunity for the user of re-embodiment (Seymour, 1998) that is not available to individuals who are congenitally impaired. That is users of both wheelchairs and prosthetic limbs that have 
acquired their impairment are able to establish a distinctive identity with their new cyborg bodies. These bodies are the hallmark of IWAS and central to the public understanding of the Paralympic movement. One explanation for this may be the fact that these athletes more than any others expose the ability in disability sport. Elite wheelchair racers over distances longer than $800 \mathrm{~m}$ are considerably faster than able-bodied runners and those athletes who wear hi-tech prostheses have higher visibility associated with their performances than ambulant athletes with cerebral palsy and visual impairment.

\section{Supercrips, Cyborgs and Les Autre}

The bodies that have been absent from this paper thus far are those that derive benefit from advances in sport science support, such as biomechanical and physiological analysis, but do not require a mobility aid such as the use of a wheelchair or prosthesis. Visually impaired, ambulant cerebral palsy and those with intellectual impairments are able to compete in sport without the use of special technologies of mobility. This relative normality can be seen as detrimental to how these groups may be treated both inside and outside the Paralympic movement. Athletes with visual impairment are relatively easily understood by the public. A high percentage of the world's population use either spectacles or contact lenses which are designed to help us better

read the world around us. As our eyesight deteriorates as a result of spending too much time at the computer or through the passage of time and old age we can understand and appreciate the difficulties associated with poor sight. As a result athletes with visual impairment are not treated as marginal in western society to the same extent as those who have cerebral palsy or an intellectual impairment (Sherrill and Williams, 1996). 
Some impairments are more difficult to understand than others, such as the uncontrollable spasticity of an individual with cerebral palsy or for those where the manifestation of their condition is only evident in social environments such as an athlete with an intellectual disability. Mobility technological intervention has a minimal role to play in managing these types of bodies to a norm that is acceptable to mainstream sporting practices. As such it is often rather difficult for the general public to see ability in some of the performances of individuals with impairments. In referring to athletes with cerebral palsy a former president of Cerebral Palsy International Sport and Recreation Association (CP-ISRA) Colin Rains stated

It's tough to say but I believe people think that athletes with cerebral palsy are not totally media friendly, visually. They can be slightly uncoordinated both in their running and their visual expressions. It is possible people find this off-putting (Mott, 2000)

The result of this can be stigmatisation of a young person with an impairment that cannot benefit from mobility technologies and therefore is unable to actively engage with the explicit cyborgification associated with athletes who use a wheelchair or prosthesis.

Following Shogan (1998) it could be argued that the mobility technology used in sport for the disabled is unnatural because it is seen as making athletes less than human. However, in light of the 'super human' results achieved through the use of either state of the art wheelchairs or prosthetic limbs, within Paralympic track and field athletics, it has become an accepted currency over the last two decades. Mobility technology allows for exceptional sporting performances in 
the sport of athletics that to some extent are celebrated by the able-bodied public but such performances are unlikely to be achieved by athletes who compete without these mobility aids. The use of what Butryn (2003) coined 'implement technology’ has made the Paralympic Games into a significant sporting spectacle.

The use of these technologies has led to a litany of supercrip stories. As highlighted earlier the supercrip can leave the observer with the sense of impossible achievement. It has been argued by Kama (2004) that the term supercrip applies either to a person with a disability that performs ordinarily in their daily life or to persons with disabilities that really excel, elevating themselves over the common person. In other words some people with impairments receive patronizing super-status just by living a normal life and as such the tag of the supercrip can be seen as a double edged sword. According to Berger

'Supercrips' are those individuals whose inspirational stories of courage and dedication, and hard work prove that it can be done, that one can defy the odds and accomplish the impossible. The concern is that these stories of success will foster unrealistic expectations about what people with disabilities can achieve, what they should be able to achieve if only they tried hard enough. Society does not need to change. It is the myth of the self-made man (Berger, 2004: 798)

By and large these narratives follow closely athletes who benefit from technological aids as it is 'easier' to see ability in a fast sprinter on Blades like Pistorius or a wheelchair racer that can 'run' a mile faster than the current able-bodied world record. However, many Paralympians who 
are highly trained and motivated athletes but do not require these technologies therefore can never live up to these ideals which appears imperative in the commercialised world of the twenty first century Paralympic Games.

More recent work by Berger highlights the role model capacity of the supercrip and clearly indicates that celebrated athletes are more than a media construction and can act as 'real' mentors (Berger, 2008). While this is a useful point Berger's research is conducted within the context of wheelchair basketball, a sport where high performance technology is also clearly evident (Berger, 2004, 2008). His conclusions would likely have been different if he had researched the ambulant cerebral palsy or visually impaired athletes who do not require mobility technologies and generally received very little media coverage. Hence their role model capacity is diminished. The same tension Berger mentions between athletes and non-athletes in his study could be made between athletes that are accepted (technology users) as supercrips and those who are not (Berger, 2008).

\section{Discussion}

At the outset of this paper I asked whether or not an increased emphasis on technology at the Paralympic Games, and the media spotlight it engenders, leads to the empowerment of the athletes with impairments. In an increasingly commercial world the technocratic ideology (Charles, 1998) that surrounds track and field athletics at the Paralympics will be hard to transform. The athletes who use wheelchairs and prosthesis are at the centre of the Paralympic movement and will be better consumers simply because they have specialist materials to purchase if they wish to compete at the highest level. The body policing (Cole, 1993, 1998) that 
goes on in mainstream high performance sport between what is acceptably human and what is not in the Paralympic world has been, paradoxically, reversed. Oscar Pistorius is a case in point. When Pistorius tried to compete in the Olympic arena his cyborg body was seen as not human enough (Hunt-Grubbe, 2007; Morrissey, 2008; Swartz and Watermeyer, 2008) yet in the Paralympic world this body is the most highly celebrated. It appears that in Paralympic track and field athletics the closer a body is to a cyborg the more capital it holds which is the opposite to the world articulated by Harraway (1991) in relation to the boundaries between humans and nonhumans. Wheelchair users and amputees who use prostheses are tied explicitly to sport technologies and therefore blur the lines between 'natural' and 'artificial' and are perhaps the best example of the cyborg in contemporary society. Butryn see the nexus between the natural and legal and the artificial and illegal as hegemonic humanness (2003: 28). Hegemonic humanism can be seen to have been practiced when Oscar Pistorius was initially excluded from competing in able-bodied athletics (Author). The restoration of his right to compete on his prosthesises was restored because he has no other option but to run on man-made legs and by the fact they were not advantaging him in the context of competition. In a sense Paralympic sport celebrates 'transgressing the taboo boundary between blood, sweat, and tears, and blood, sweat and gears’(Butryn, 2003: 28). Here the cyborg wheelchair user and the prosthetic limb wearer are the role models and supercrips the Paralympic movement triumphs, in a way that Olympic and other mainstream sport has failed to achieve. This is largely because the Paralympics Games was designed to celebrate difference that is distinct from the able-bodied norm. Yet today it appears that Paralympic difference must increasingly take on a cyborg form. 
Where does this leave les autre? They certainly have a part to play in the Paralympic movement, but the more marginal the physicality of the body, the further away it is from the potential of cyborgification and the more likely a tragic rather than a heroic allegory will follow them. This analysis tells us a great deal about the politics of disablement. While it is considered an infringement for the able to become too cyborg, for the disabled it is highly advantageous because technology can normalise their 'inferior' bodies to the point where in the case of elite wheelchair racers they can produce super-human results. Of course there is a tension here. MacIntyre (1999) tells us that vulnerability and affliction and the related facts of dependence are central to the human condition. The susceptibility to injury and misery, distress and pain is likely to befall us all at some point in our existence. We all will be reliant on others from time to time. It begs the question why impaired bodies are so harshly disabled by society and, at least in the context of Paralympic sport, only those that are cyborgs are celebrated at length. Of these cyborgs the winners are held up on a pedestal as supercrips.

\section{Conclusion}

The classification system at the centre of the Paralympic movement was established by the now defunct ISMWSF but lives on in IWAS. This system classifies bodies that use wheelchairs to compete in the sport of athletics and creates les autre who are unable to use this mobility technology. In the last twenty years the associated development of biomechanically and ergonomically responsive prostheses has meant that many athletes who in the past would have competed from a wheelchair are now able to compete from a standing position. While the development of mobility technology that enhances sport performance is understandably beneficial for the impairment groups concerned (at least for those that can afford them), it 
marginalises further those athletes that do not use technologies directly in their competitive performance. Because the high-end wheelchair athlete is able to perform at the same level or better than an able-bodied athlete, to the public the abilities of these athletes is obvious. On the other hand an athlete that has cerebral palsy which affects both legs and runs 100m much slower than his/her able-bodied counterpart it might be difficult to see their ability.

The possibility of a re-embodiment for certain athletes with disabilities is provided through acquiring expensive sporting technologies. This economic exclusion makes ineligible much of the world's population of potential Paralympians. In elite sport for the disabled, there are increasing numbers of athletes with mechanical, artificially designed bodies creating new sporting potential. These athletes are the most celebrated in part because the sport for the disabled movement developed around them. The technology they use has the capacity to 'normalise' their bodies, and in so doing produces 'sporting cyborgs'. Unlike in mainstream sport these athletes are celebrated both inside and increasingly outside the Paralympic movement. A technocentric ideology has led to a cyborgification that is celebrated within Paralympic sport and has made celebrities of the athletes who are successful in using the state of the art movement technologies to achieve super performances (Author). Such elevated status of handpicked cyborgs can be problematic for the communities of impaired individuals who can never achieve such a position. As Kama argues:

(w)ell-known, successful disabled people are put on a pedestal for their demonstrated ability to triumph. This triumph is used to validate the disabled individual and to alter societal perceptions. Consequently, the wish to see disabled 
who 'have done it' is particularly intense while the pitiful disabled trigger antipathy because they reproduce and reinforce disabled people's inferior positionality and exclusion (2004:447)

The celebration of the supercrip, that is manifest in the cyborg bodies of the best wheelchair and prosthetic wearing athletes, is good for the individuals placed on the pedestal but may lead to the (dis)empowerment of other athletes with impairment who cannot take advantage of the explicit use of technology. Ultimately the Paralympics risk becoming a show of technology, rather than a show of athleticism, leaving behind those from the developing world without performanceenhancing technology at their disposal, and those from the west whose bodies are inappropriate

for its use. Technological advancement in relation to Paralympic sport is not dissimilar to other changes in society; it is clearly a mixed blessing. Technology empowers some while leaving the status of others at best unaltered and at worst increasing their liminality.

\section{Refernces}

Berger, R. J. (2004)‘Pushing Forward: disability, basketball, and me’, Qualitative Inquiry. Vol. 10: 794-810.

Berger, R. J. (2008) ‘Disability and the Dedicated Wheelchair Athlete: beyond the "Supercrip” critique', Journal of Contemporary Ethnography. Vol. 37(6): 647-678.

Burkett, B. (2010) 'Technology in Paralympic Sport: performance enhancement or essential for performance’ British Journal of Sports Medicine. Vol. 44: 215-220. 
Butryn, T. M. (2002) ‘Cyborg Horizons: Sport and the ethics of self-technologization’, In Miah, A. and Easson, S. (eds.) Sport, Technology: History, philosophy, and policy. Oxford: Elsevier Science. p. 111-134.

Butryn, T. M. (2003)‘Posthuman Podiums: Cyborg Narratives of Elite Track and Field Athletes’, Sociology of Sport Journal Vol. 20:17-39.

Chaloner, E. J., Flora, H. S., and Ham, R. J. (2001) 'Amputations at the London Hospital 18521857', Journal of the Royal Society of Medicine. Vol. 94: 409-412.

Charles, J. M. 1998) ‘Technology and the Body of Knowledge’. Quest, Vol. 50 : 379-388.

Cole, C.L. (1993) 'Resisting the Canon: Feminist cultural studies, sport, and technologies of the body’, Journal of Sport and Social Issues, Vol. 17: 77-97.

Cole, C.L. (1998)‘Addiction, exercise, and cyborgs: Technologies and deviant bodies’, In Rail, G. (ed.) Sport and Postmodern Times, Albany: State University of New York Press. p. 261-275.

Davis, R and Cooper, R. (1999) ‘Technology for Disabilities’, British Medical Journal Vol. 319 Nov. $13: 1-4$

DesGroseillers, J. -P., Desjardins, J. -P., Germain, J. -P., Krol, A. L. (1978)`Dermatologic Problems in Amputees', Canadian Medical Association Journal. Vol. 118, p. 535-537.

Dupré, J. (2006)‘Scientific Classification’, Theory, Culture and Society, Vol. 23 (2-3) p. 30-32.

Frossard, L., O’Riordan, A. and Goodman, S. (2006)‘Applied Biomechanics for Evidence Based training of Australian Elite Seated Throwers' International Council of Sport Science and Physical Education.

Haller, B. (2000) 'If they limp, they lead? news representations and the hierarchy of disability images'. In D. O. Braithwaite, \& T. L. Thompson (Eds.), Handbook of communication and 
people with disabilities : Research and application (pp. 273-288). Mahwah, N.J.: Lawrence Erlbaum Associates, Publishers.

Haraway, D.J. (1991) Simians, cyborgs, and women: The reinvention of nature. London: Routledge .

Hoberman, J. (1992) Mortal Engines: the science of human performance and the dehumanization of sport. Oxford: The Free Press.

Hughes, B. (2000) 'Medicine and the Aesthetic Invalidation of Disabled People', Disability and Society. Vol. 15 (4) p.555-568.

Hunt-Grubbe, C. (2007) ‘The Blade Runner Generation’, The Sunday Times: London at http://timesonline.co.uk/tol/life/_and_style/health/article2079637.ece?print=yes. (accessed on July 21, 2007)

Kama, A. (2004). 'Supercrips versus the pitiful handicapped: Reception of disabling images by disabled audience members’ Communications, 29(4), 447-466.

MacIntyre, A. (1999)Dependent Rational Animals: Why human beings need the virtues. Chicago: Open Court.

Mastro, J. V. M., Burton, A. W., Rosendahl, M., \& Sherrill, C. (1996) 'Attitudes of elite athletes with impairments toward one another: A hierarchy of preference.' Adapted Physical Activity Quarterly, 13(2), 197-210.

Morrissey, R. (2008) ‘Fast-Moving Technology: prosthetics, physical ability merging in a blur’, Chicago Tribune, at http://dispatch.com/live/contentbe/dispatch/2008/02/03/20080203-

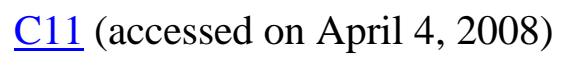


Mott, S. (2000)‘Impaired logic keeps heroes off the stage’ The Daily Telegraph. December 11, 2000.

Rossi, L.F.A (1974) ‘Rehabilitation Following Below-knee Amputation’, Proceeds of the Royal Society of Medicine. Vol. 67,(1974): 37-38.

Schell, L. A. \& Rodriguez, S. (2001) 'Subverting bodies/ ambivalent representations: Media analysis of Paralympian, Hope Lewellen.' Sociology of Sport Journal, Vol. 18 p. 127135.

Seymour, W. (1998) Remaking the Body: Rehabilitation and Change. London: Routledge .

Sherrill, C. (1999) 'Disability sport and classification theory: A new era.' Adapted Physical Activity Quarterly, Vol. 16: 206-215.

Sherrill, C. and Williams, T. (1996)`Disability and Sport: Psychosocial Perspectives on Inclusion, Integration and Participation’. In Sport Science Review. Vol. 5 (1): 42-64.

Shogun, D. (1998)‘'The Social Construction of Disability: the impact of statistics and technology,' Adapted Physical Activity Quarterly, Vol. 15: 269-277.

Swartz, L. And Watermayer, B. (2008)`Cyborg anxiety: Oscar Pistorius and the boundaries of what it means to be human' Disability and Society. Vol. 23(2):187-190.

Tweedy, S.M. and Vanlandewijick. Y.C. (2009) ‘International Paralympic Committee Position Stand - Background and scientific rationale for Classification in Paralympic Sport', British Journal of Sports Medicine. Online 10, 29.

Webling, D. D’A., and Fahrer, M. (1986) ‘Early Bent Knee Prostheses: ancestors of K9’, British Medical Journal. Vol. 293:1636-1637.

Yilla, A. B. (2000)‘Enhancing Wheelchair Sport Performance’, in Winnock, J. ed. Adapted Physical Education and Sport. $3^{\text {rd }}$ edition. Leeds: Human Kinetics. p. 419-431. 


\section{Notes}

${ }^{1} \mathrm{I}$ am aware this approach is not favoured in social scientific circles but it is important here to accurately reflect Paralympic culture.

2 The federations, namely the Cerebral Palsy International Sport and Recreation Association (CP-ISRA), International Blind Sport Association (IBSA), International Sports Federation for Persons with Intellectual Disability (INAS-FID), and, the International Wheelchair and Amputee Sport Association (IWAS). This is a federation that was launched in September 2004 at the Athens Paralympic Games. It is the result of a merger of two federations, the International Stoke Mandeville Wheelchair Sports Federation (ISMWSF) and the International Sport Organisation for the Disabled (ISOD), that have been part of the IPC since its inception.

${ }^{3}$ Les Autres is a French phrase used within disability sport circles meaning 'the others'. Originally the term refers to athletes with a disability who did not directly fit into the classification system established by IWAS. Today les autres is used to highlight any athlete who is not specifically referred to in the classification systems of the IOSDs and that is able to be slotted into an existing classification system. I use the term here specifically to refer to athletes with a disability who do not use either a wheelchair or prosthesis while competing in athletics. ${ }^{4}$ In the early days of Paralympic sport athletes with amputations would have more often than not competed from a wheelchair and as such the group of athletes I consider to be at the centre of the Paralympic movement are both those with spinal cord injuries and amputations.

${ }^{5}$ Club is an event for class F32/F51 athletes who either have very involved and severe cerebral palsy (F32) or a very high lesion on their spinal cord (F51) and as a result throwing a javelin is impractical and dangerous.

${ }^{6}$ The connection between the prosthesis and the upper body obviously does have gravity to deal with, but the lack of 'weight bearing' means that pressure ulcers and the like are less troublesome. Also arm prosthesis are much less prevalent in the sport of track and field athletics. ${ }^{7}$ I use the term 'able-bodied' here because it is the term used by athletes within the cultural context of the Paralympic 